\title{
Morphometry of Malleus a Possible Tool in Sex Determination
}

\author{
Kamal Singh $^{1 *}$, Sudha Chhabra1', Basant Lal Sirohiwal ${ }^{2}$ and SPS Yadav ${ }^{3}$
}

${ }^{1}$ Department of Anatomy, Pt. B. D. Sharma Post Graduate Institute of Medical Sciences, Rohtak-124001, Haryana, India

${ }^{2}$ Department of Forensic Medicine, Pt. B. D. Sharma Post Graduate Institute of Medical Sciences, Rohtak-124001, Haryana, India

${ }^{3}$ Department of Ottolarygology, Pt. B. D. Sharma Post Graduate Institute of Medical Sciences, Rohtak-124001, Haryana, India

\begin{abstract}
The sex is estimated in the dead bodies mainly from big intact bones like skull, mandible, pelvis and long bones etc. The malleus is housed in the middle ear, so, remain well protected even in the mutilated bodies and although small but strongest of all the ossicles. We studied the morphometry of the 120 human mallei from 60 cadavers (30 male and 30 female) with the aim to know the sexual dimorphism in north Indian population. Out of various parameters the total length and the length of the handle were found to be of significant value in estimation of sex.
\end{abstract}

Keywords: Identification; Malleus; Middle ear; Sex determination; Skeletal remains

\section{Introduction}

Determination of sex in the inadequate skeletal remains of the bodies is a challenging task even for experienced forensic experts. Sex determination is the first essential step in medicolegal autopsies for positive identification which is usually done from long bones, skull, mandible \& pelvis [1]; however it is very difficult in an unidentified decomposed/mutilated body [2]. Many a time, even the most skilled expert is filled with trepidation while deciding the sex in inadequate remains of a body. The ear ossicles remain protected in the petrous part of the temporal bone and can be retrieved from the remnants of even severely mutilated bodies. Although the dissection of cadaveric temporal bone is a must for trainee otolaryngologists, however, forensic experts remain oblivious to ear ossicles as the review of literature revealed no study to utilize the morphometry of malleus for sex determination. The malleus is the largest ossicles and comprises of head, neck, handle \&anterior and lateral processes (Figure 1). The head (capitulum mallei) forms the large ovoid upper end of the bone. It articulates posteriorly with the incus, with a saddle shaped articular facet. Opposite the constriction, the lower margin of the facet projects in the form of a process, the spur of the malleus. The neck (collum mallei) forms the narrow portion between the head and the two processes. The handle (manubrium mallei) of the malleus is connected laterally with the tympanic membrane. The lateral process is conical projection from the root of the handle of malleus [3]. This study was a humble attempt to unravel the possible differences with regard to gender and bilateral morphological variations as the earlier reports found hardly any difference in the malleus [4].

\section{Material and Methods}

The present study was conducted on sixty unidentified cadavers in different stages of decomposition during medicolegal postmortem examination. In these bodies the ear ossicles were easily removed manually after dissection of the petrous part of temporal bone and 120 , malleus were retrieved and the dimensions of the malleus were studied from selected points as depicted in the diagrams (Figure 1). These were measured by the digital vernier caliper with the least count of $0.01 \mathrm{~mm}$. The weights of the bones were measured by the electronic micro-balance of 'Sartorius CP224S' model with the least readability of $0.1 \mathrm{mg}$. All the measurements were taken by the same investigator. Each reading was taken thrice and the mean of all the three was taken to rule out any inadvertent error. The results of the study were computed and analyzed with SPSS software 16.

\section{The parameters of the malleus studied:}

i. Total length (a-b): Maximal distance between the top of the head and the end of the handle;

ii. Length of handle (b-c): Distance from the end of the lateral process to the end of handle;

iii. Length of head and neck (a-c): Maximal distance between the top of the head and the end of the lateral process;

iv. Weight (mg).

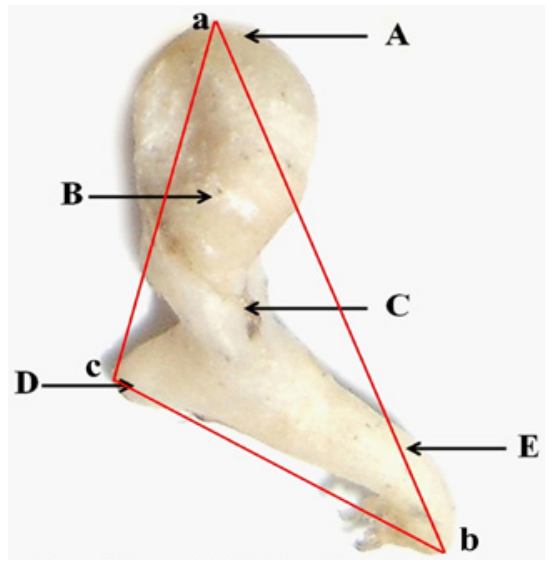

Figure 1: Photograph of Malleus (enlarged view) showing: (A) Head, (B) Facet, (C) Neck, (D) Lateral Process and (E) Handle Total length (a-b), Length of handle $(b-c)$, Length of head and neck (a-c).

*Corresponding author: Kamal Singh, Department of Anatomy, University of Health Sciences, Rohtak-124001, Haryana, India, Tel: 09812531007; E-mail: drkamalanatomy@gmail.com

Received February 02, 2012; Accepted June 11, 2012; Published June 13, 2012

Citation: Singh K, Chhabra S, Sirohiwal BL, Yadav SPS (2012) Morphometry of Malleus a Possible Tool in Sex Determination. J Forensic Res 3:152. doi:10.4172/2157-7145.1000152

Copyright: (c) 2012 Singh K, et al. This is an open-access article distributed unde the terms of the Creative Commons Attribution License, which permits unrestricted use, distribution, and reproduction in any medium, provided the original author and source are credited. 


\section{Observations and Results}

We observed no statistical significance difference on comparison of morphometric parameters of malleus of right and left side when analyzed collectively from both the sexes (Table 1). But found statistical significant difference (p 0.014) in the total length of malleus between male and female on right side alone and similarly a significant difference was observed in the length of handle of malleus between male and female on right side ( $\mathrm{p}-0.02)$ as well as on left side ( $\mathrm{p}-0.014)$ (Table 2). However other parameters like length of head and neck, and weight of malleus were not significantly different in two sexes on right as well as left side. The findings of these two parameters were not consistent with earlier research but were having meaningful differences statistically in both sexes in north Indian population indicating that malleus morphometry is different in two sexes. However, parameters like length of head and neck and weight were found to be statistically insignificant $(p>0.05)$ in determination of sex. Moreover, there were no statistical significant differences observed in male as well as female when compared bilaterally. From the analysis of the different parameters of malleus it was observed that the total length of right malleus and length of handle of both sides of malleus are the fairly good criteria to significant test in sexual dimorphism.

\section{Discussion}

Ossicles play an important role in hearing. Malleus provides 1.3 time mechanical advantage due to lever ratio, hence potentiates sound energy by that ratio. Morphometric analysis of ear ossicles has been the subject of interest since mid fifteenth century [5]. Studies on embryogenesis of hearing [6] have shown that ear differs from individual to individual with a saying that 'No two ears are same' [7]. The morphometry of ossicles has been studied by various authors more so in males [8-10]. Some authors have studied the morphometry irrespective of sides e.g. Arensburg et al. from Israel took ossicles of either left or right side in an individual and not from both sides. They studied malleus in different races of different era. They reported malleus length $7.7,8.1$, and $7.8 \mathrm{~mm}$ and manubrium length of $4.5,4.6$, and 4.4 $\mathrm{mm}$ in three races [5]. Harneja et al. reported the malleus length of $7.15 \mathrm{~mm}$ and manubrium length of $4.22 \mathrm{~mm}$ [11]. Our findings are comparable to these studies. Vincentiis \& Cimino studied a large series which included infants, juvenile, adult male \& females. They reported the length of $9 \mathrm{~mm}$ in infants and $9.41 \mathrm{~mm}$ in adults with a median of $9.20 \mathrm{~mm}$ which is comparable to our findings; however they observed no significant difference with age and sex [12]. Harneja et al., reported the mean weight of $23.65 \mathrm{mg}$ from India, Vincentiis \& Cimino reported a mean weight of $23.05 \mathrm{mg}$, Oschman \& Meiring from South Africa as $22 \mathrm{mg}[4,11,12]$. Our findings (Table 1) are almost similar to earlier reports, although previous authors didn't weigh separately of right \& left side.

Various authors previously didn't find any significant difference on both sides or either sex in their studies [5,13-15]. However we observed that total length of malleus on right side and length of handle of malleus on both sides was significantly sexually dimorphic. It is difficult to understand that total length of malleus is more on right than left side. We studied the morphometry in North Indian population who are Indo-Aryan descendents. They are predominantly right handed and it is surmised that due to use of phone on right side, the right sided ossicles are more in action as compared to left possibly leading on to a difference in total length of malleus between right \& left side. Further the bones are slightly bigger as whole on right side in the upper part e.g. humerus as compared to left. We observed that the length of handle of malleus on both sides was significantly more in males as compared to females which may be due to the simple fact that all bones are larger in males. However this has not been reported in literature. This could be due to racial difference in various studies as compared to the present

\begin{tabular}{|l|c|c|}
\hline Morphometric Parameter & $\begin{array}{c}\text { Right } \\
\text { Mean } \pm \text { SD }\end{array}$ & $\begin{array}{c}\text { Left } \\
\text { Mean } \pm \text { SD }\end{array}$ \\
\hline Total Length $(\mathbf{m m})$ & $7.947 \pm 0.415$ & $7.9467 \pm 0.401$ \\
\hline Length of Handle $(\mathbf{m m})$ & $4.762 \pm 0.45139$ & $4.726 \pm 0.376$ \\
\hline Length of Head and Neck $(\mathbf{m m})$ & $5.237 \pm 0.3409$ & $5.2172 \pm 0.400$ \\
\hline Weight $(\mathbf{m g})$ & $22.920 \pm 3.324$ & $23.030 \pm 3.454$ \\
\hline
\end{tabular}

${ }^{*} \mathrm{P}$-value of less than 0.05 was regarded as statistically significant

Table 1: Comparison of Morphometric Parameters of Right and Left Mallei.

\begin{tabular}{|c|c|c|c|c|c|c|c|c|c|c|}
\hline \multirow[t]{2}{*}{$\begin{array}{l}\text { Morphometric } \\
\text { Parameter }\end{array}$} & \multicolumn{2}{|c|}{$\begin{array}{c}\text { Right } \\
\text { Mean } \pm \text { SD }\end{array}$} & \multicolumn{2}{|c|}{$\begin{array}{c}\text { Right } \\
\text { Coefficient of } \\
\text { Variation (\%) }\end{array}$} & \multirow{2}{*}{$\begin{array}{l}\text { Right P } \\
\text { Value }\end{array}$} & \multicolumn{2}{|c|}{$\begin{array}{c}\text { Left } \\
\text { Mean } \pm \text { SD }\end{array}$} & \multicolumn{2}{|c|}{\begin{tabular}{l}
\multicolumn{1}{c}{ Left } \\
Coefficient of \\
Variation (\%)
\end{tabular}} & \multirow[t]{2}{*}{$\begin{array}{l}\text { Left P } \\
\text { Value }\end{array}$} \\
\hline & Male & Female & Male & Female & & Male & Female & Male & Female & \\
\hline Total Length $(\mathrm{mm})$ & $8.078 \pm 0.453$ & $7.817 \pm 0.334$ & 5.61 & 4.27 & 0.014 & $8.045 \pm 0.471$ & $7.848 \pm 0.294$ & 5.85 & 3.74 & 0.057 \\
\hline $\begin{array}{l}\text { Length of Handle } \\
\qquad(\mathrm{mm})\end{array}$ & $4.896 \pm 0.384$ & $4.628 \pm 0.480$ & 7.84 & 10.36 & 0.02 & $4.844 \pm 0.341$ & $4.608 \pm 0.379$ & 7.04 & 8.22 & 0.014 \\
\hline $\begin{array}{l}\text { Length of Head } \\
\text { and Neck }(\mathrm{mm})\end{array}$ & $5.194 \pm 0.363$ & $5.280 \pm 0.318$ & 6.98 & 6.02 & 0.329 & $5.210 \pm 0.462$ & $5.224 \pm 0.335$ & 8.88 & 6.41 & 0.891 \\
\hline Weight (mg) & $23.393 \pm 3.831$ & $22.447 \pm 2.710$ & 16.38 & 12.07 & 0.274 & $23.543 \pm 3.830$ & $22.517 \pm 3.011$ & 16.27 & 13.37 & 0.253 \\
\hline
\end{tabular}

*P-value of less than 0.05 was regarded as statistically significant and is indicated in bold italics underlined

Table 2: Comparison of Morphometric Parameters of Malleus in Males and Females on Two sides. 
Citation: Singh K, Chhabra S, Sirohiwal BL, Yadav SPS (2012) Morphometry of Malleus a Possible Tool in Sex Determination. J Forensic Res 3:152. doi:10.4172/2157-7145.1000152

Page 3 of 3

one. Oschman \& Meiring [4] found statistical significant difference between Negroid and Caucasoid races, however no sexual difference was observed by them.

Our analysis of sexual dimorphism in malleus with respect to total length of malleus of right side and length of handle on both sides revealed subtle sexual dimorphism. Thus, this study may turn out to be a potential source of forensic investigation for evaluation of sex in severely mutilated and decomposed bodies during postmortem examination. However, it is pertinent to say that these finding are to be replicated in larger population by other investigators and from different parts of the world. Further, the retrieval and preservation of the malleus is to be standardized.

\section{References}

1. Krogman WM (1962) The Human Skeleton In Forensic Medicine. (1stEdn), Charles C Thomas, Springfield, Illinois, USA

2. Kranioti EF, Michalodimitrakis M (2009) Sexual dimorphism of the humerus in contemporary Cretans--a population-specific study and a review of the literature*. J Forensic Sci 54: 996-1000.

3. Standring $S(2005)$ The anatomical basis of clinical practice. (39 $9^{\text {th }}$ Edn) Elsevier, Edinburg, Churchill livingstone.

4. Oschman Z, Meiring JH (1991) A Morphometric and comparative study of the malleus. Acta Anat (Basel) 142: 60-61.

5. Arensburg B, Harell M, Nathan H (1981) The Human Middle Ear Ossicles:

\section{Morphometry and taxonomic implications. J Hum Evol 10: 199-205.}

6. Anson BJ, Hanson JS, Richany SF (1960) Early embryology of the auditory ossicles and associated structures in relation to certain anomalies observed clinically. Ann Otol Rhinol Laryngol 69: 427-447.

7. HOUGH JV (1963) CONGENITAL MALFORMATIONS OF THE MIDDLE EAR. Arch Otolaryngol 78: 335-343.

8. Aycan K, Unur E, Bozkir MG, et al. (1990) Anatomical study of malleus. J of Health Sci 1: 152-158.

9. Unur E, Ullger H, Ekinci N (2002) Morphometrical and morphological variations of middle ear ossicles in the newborn. Erciyes Medical Journal 24: 57-63.

10. Natekar PE, De Souza FM (2010) Indices of malleus in reconstructive surgery. Indian J Otol 16: 36-40.

11. Harneja NK, Chaturvedi RP (1973) A study of the human ear ossicles. Indian J Otol 25: 154-160.

12. De vincentiis I, Cimino A (1957) [Morphology, measurements and weight of the middle ear ossicles]. Riv Biol 49: 181-204.

13. Urbantschitsch V (1876) Zur Anatomie der Gehorknochelchen des Menschen. Archiz Fur Ohrenheilkundv 11: 1.

14. Bouchet A, Giraud M (1968) Contribution a l'etude orphologique et radiologique des osselets de l'ouie. Compte rendu de l' Association des Anatomists 53 Congres 141: 588-600.

15. Siori MS, Monchietto MJ, Masali M (1995) Morphometrics of human auditory ossicles from Antinoe Necropolis (Egypt). Int J Anthropol 10: 29-36. 